\title{
A novel grade-lymph node ratio model predicts the prognosis of the advanced gastric cancer patients after neoadjuvant radiotherapy
}

\author{
Jianjun Liu ${ }^{1, *}$, Mingxue Su ${ }^{2, *}$, Jing Wang ${ }^{3, *}$, Gan Zhang ${ }^{1}$, Jing Zhou ${ }^{1}$, Anqing Zhang ${ }^{1}$, \\ Zixue Ren ${ }^{1}$, Xucai Zheng ${ }^{1}$, Shikai Hong ${ }^{1}$, Shengying Wang ${ }^{1}$ and Rongxin Zhang ${ }^{1}$ \\ ${ }^{1}$ Department of Head - Neck and Thoracic Surgery, Anhui Provincial Cancer Hospital, West branch of Anhui Province Hospital, \\ Hefei, China \\ 2 Department of Infectious Disease Epidemiology, Lu'an People's Hospital, Lu'an, China \\ ${ }^{3}$ Department of Urologic Surgery, Anhui Provincial Cancer Hospital, West branch of Anhui Province Hospital, Hefei, China \\ * These authors have contributed equally to this work \\ Correspondence to: Rongxin Zhang, email: rongxzhang@126.com
}

Shengying Wang, email: Shengywang@163.com

Keywords: neoadjuvant radiotherapy; gastric cancer; survival analysis; SEER

Received: August 23, $2016 \quad$ Accepted: October 05, 2016

Published: October 11, 2016

\section{ABSTRACT}

Although local advanced gastric cancer (AGC) could benefit from neoadjuvant radiotherapy (NRT), there are few studies evaluating patients' survival after NRT. In current study, we aimed to investigate the value of prognostic factors in AGC patients after NRT and to evaluate whether post-therapy pathological characteristics were predictive factors in these patients. We retrospectively analyzed AGC patients who underwent NRT from Surveillance, Epidemiology, and End Results (SEER) Database. The patients' clinical and post-therapy pathological characteristics were analyzed. The best cutoff points for continuous variables were identified by $X$-tile. The discrimination of risk factors were compared by receiver operating characteristic (ROC) curve. As a result, 1,429 AGC patients were included into this study. In the multivariate analysis, the Iymph nodes status and histology grade were significant risk factors for DSS (disease special survival). Then, we propose a novel Grade-lymph node Ratio (GR) staging system for the AGC patients' survival prognosis. Clearly, the new G-R staging system has a more-accurate 3-year and 5-year DSS prediction than the AJCC staging system ( $p=0.001,0.007$, respectively). In conclusions, the current large, general population-based study demonstrated that the G-R staging system resulting in more-accurate DSS prediction. It could be regarded as a reliable classification for AGC patients after NRT in future.

\section{INTRODUCTION}

Gastric cancer is the fourth most common malignancy and second leading cause of cancer-related death worldwide. [1] In 2014, approximately 22,220 new cases were diagnosed and 10,990 deaths attributed to gastric cancer in United States. Although the incidence has declined recently, the 5-year survival was less than $30 \%$. [2, 3]

Completed resection with lymph node dissection is the only potential curative treatment for resectable cancer. [4] However, the cancer symptoms usually were not obvious in early stage, most patients were diagnosed with advanced stage in most countries. Recently, the MAGIC trials demonstrated that the neoadjuvant chemotherapy improved survival for AGC patients. [5] Meanwhile, several phase I/II trails also demonstrated a survival benefit for AGC patients after NRT. [6-8] Indeed, the neoadjuvant therapy can achieve a clinical downstaging before resection and increase the possibility of $\mathrm{R} 0$ resection for AGC patients. [9-11] As a result, the neoadjuvant therapy were widely used for potentially resectable AGC before surgery.

Based on those promising results, the neoadjuvant 
Table 1: Characteristic of patients from SEER database

\begin{tabular}{|c|c|c|}
\hline \multirow[t]{2}{*}{ Characteristic } & \multicolumn{2}{|c|}{ Patients $(n=1,429)$} \\
\hline & NO. & $\%$ \\
\hline \multicolumn{3}{|l|}{ Age (years) } \\
\hline Median & \multicolumn{2}{|c|}{$60.8 \pm 10.4$} \\
\hline Range & \multicolumn{2}{|c|}{14 to 88} \\
\hline \multicolumn{3}{|l|}{ Gender } \\
\hline Male & 1206 & 84.4 \\
\hline Female & 223 & 15.6 \\
\hline \multicolumn{3}{|l|}{ Race } \\
\hline White & 1278 & 89.4 \\
\hline Black & 61 & 4.3 \\
\hline AI & 18 & 1.3 \\
\hline API & 70 & 4.9 \\
\hline Unknown & 2 & 0.1 \\
\hline \multicolumn{3}{|l|}{ Tumor size $(\mathrm{cm})$} \\
\hline $\operatorname{Median}(n=1027)$ & \multicolumn{2}{|c|}{$4.6 \pm 3.4$} \\
\hline Range & \multicolumn{2}{|c|}{0.1 to 50} \\
\hline \multicolumn{3}{|l|}{ Tumor location } \\
\hline Cardia & 1299 & 90.9 \\
\hline Fundus & 9 & 0.6 \\
\hline Body & 17 & 1.2 \\
\hline Antrum & 32 & 2.2 \\
\hline Pylorus & 4 & 0.3 \\
\hline Lesser curvature & 29 & 2.0 \\
\hline Greater curvature & 9 & 0.6 \\
\hline Overlapping & 18 & 1.3 \\
\hline Unknown & 12 & 0.8 \\
\hline \multicolumn{3}{|l|}{ Grade } \\
\hline Well differentiated & 62 & 4.3 \\
\hline Moderately differentiated & 510 & 35.7 \\
\hline Poorly differentiated & 827 & 57.9 \\
\hline Undifferentiated & 30 & 2.1 \\
\hline \multicolumn{3}{|l|}{ Depth of invasion } \\
\hline Mucosa or submucosa & 134 & 9.4 \\
\hline Proper muscle & 215 & 15.0 \\
\hline Subserosa & 667 & 46.7 \\
\hline Serosa & 260 & 18.2 \\
\hline Adjacent invasion & 125 & 8.7 \\
\hline Unknown & 28 & 2.0 \\
\hline \multicolumn{3}{|l|}{ Number of positive LN. } \\
\hline 0 & 757 & 53.0 \\
\hline 1 to 2 & 342 & 23.9 \\
\hline 3 to 6 & 231 & 16.2 \\
\hline 7 to 15 & 81 & 5.7 \\
\hline 16 or more & 18 & 1.3 \\
\hline Positive LN (Mean \pm SD) & \multicolumn{2}{|c|}{$1.8 \pm 3.3$} \\
\hline Total LN $($ Mean \pm SD) $(\mathrm{n}=1411)$ & \multicolumn{2}{|c|}{$14.3 \pm 9.9$} \\
\hline \multicolumn{3}{|l|}{ AJCC Stage } \\
\hline IA & 100 & 7.0 \\
\hline
\end{tabular}




\begin{tabular}{|l|l|l|}
\hline IB & 146 & 10.2 \\
\hline IIA & 410 & 28.7 \\
\hline IIB & 307 & 21.5 \\
\hline IIIA & 196 & 13.7 \\
\hline IIIB & 173 & 12.1 \\
\hline IIIC & 69 & 4.8 \\
\hline Unknown & 28 & 2.0 \\
\hline Adjuvant radiotherapy & & \\
\hline Yes & 60 & 4.2 \\
\hline No & 1369 & 95.8 \\
\hline
\end{tabular}

Abbreviations: AI, American Indian or Alaska Native; API, Asian or Pacific Islander; LN, lymph node; AJCC, American Joint Committee on Cancer.

therapy may be a potential standard treatments for AGC patients. However, the prognostic value of post-therapy pathologic characteristic were still unclear, especially in patients underwent NRT. [10, 12-15] In current study, we aimed to investigate the value of prognostic factors in AGC patients and to evaluate whether post-therapy pathological characteristics were predictive factors of survival in these patients.

\section{RESULTS}

\section{Patients and demographics}

A total of 1,429 patients between January 1998 and November 2013 in the SEER database who met all the inclusion criteria were analyzed in current study. The patients' characteristics were listed in Table 1. Overall, there were 1,206 male patients and 223 female patients, and the median age was 60.8 years old. There were also 60 (4.2\%) patients who received adjuvant radiotherapy after curative resection. The mean number of positive lymph node was $1.8 \pm 3.3$, and the mean total examined number of lymph node was $14.3 \pm 9.9$. With a median follow-up of 31.9 months, there were $760(53.2 \%)$ patients died before the analysis of the present study, and $102(13.4 \%)$ patients of them were died because of other causes.

\section{Survival and lymph node ratio categories}

The median DSS for all patients was 35 months, and the 1-year DSS, 3-year DSS, 5-year DSS were 83.0\%, $48.9 \%$ and $39.0 \%$, respectively. Lymph node ratio was

B

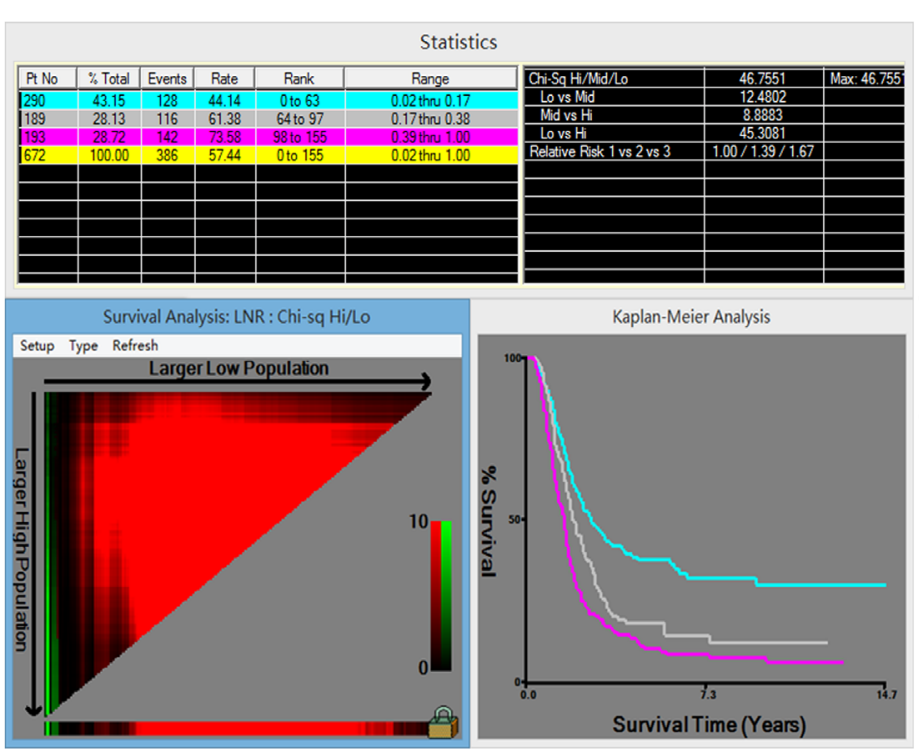

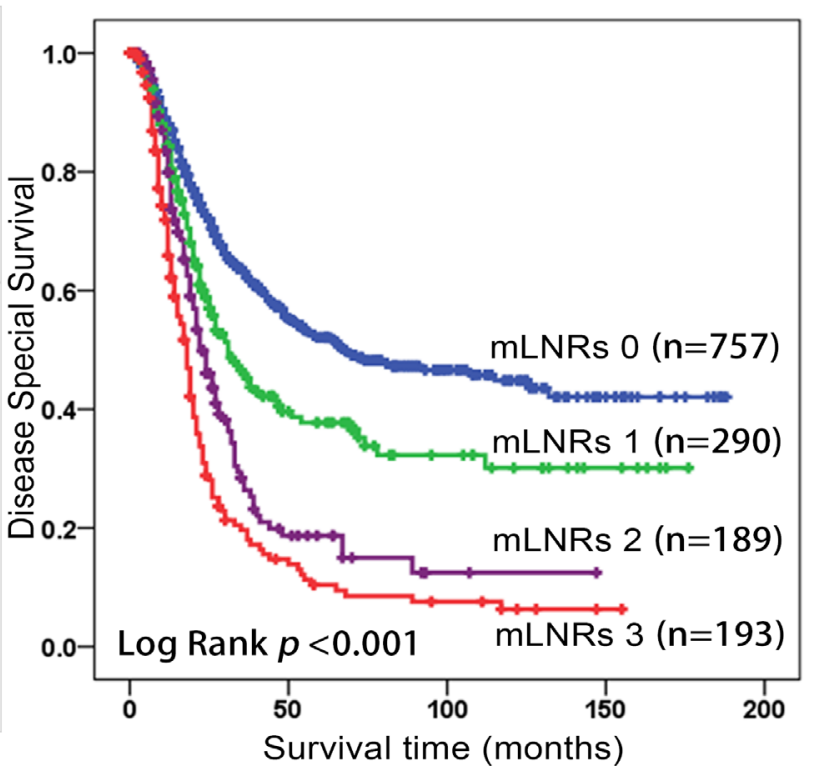

Figure 1: X-tile analysis identified the best cutoff points for mLNR A., and validated by Kaplan-Meier Curve B. Abbreviation: mLNR, metastatic lymph node ratio. 
Table 2: Prognostic factors for DSS of all the patients

\begin{tabular}{|c|c|c|c|c|c|c|}
\hline & \multicolumn{3}{|c|}{ Univariate analysis } & \multicolumn{3}{|c|}{ Multivariate Analysis } \\
\hline & HR & $95 \%$ CI & $p$ & HR & $95 \%$ CI & $p$ \\
\hline Age & 1.005 & 0.998 to 1.013 & 0.167 & & & \\
\hline Gender (Female / Male) & 0.879 & 0.708 to 1.091 & 0.243 & & & \\
\hline Race & & & 0.062 & & & \\
\hline $\begin{array}{l}\text { API/ } \\
\text { nonAPI }\end{array}$ & 0.762 & 0.573 to 1.014 & & & & \\
\hline Location & & & 0.939 & & & \\
\hline Antrum & ref & & & & & \\
\hline Fundus & 0.771 & 0.220 to 2.707 & & & & \\
\hline Body & 1.255 & 0.520 to 3.029 & & & & \\
\hline Cardia & 1.336 & 0.771 to 2.315 & & & & \\
\hline Pylorus & 1.464 & 0.417 to 5.139 & & & & \\
\hline Lesser curvature & 1.462 & 0.678 to 3.155 & & & & \\
\hline Greater curvature & 1.371 & 0.488 to 3.847 & & & & \\
\hline Overlapping & 1.547 & 0.661 to 3.620 & & & & \\
\hline Grade & & & $<0.001$ & & & 0.010 \\
\hline $\begin{array}{|ll|}\text { Well } & \text { /Moderately } \\
\text { differentiated }\end{array}$ & 0714 & 0608 to 0838 & & 0807 & 0686 to 0050 & \\
\hline $\begin{array}{l}\text { Poorly differentiated/ } \\
\text { Undifferentiated }\end{array}$ & 0.114 & 0.008 to 0.838 & & 0.801 & 0.080 to 0.950 & \\
\hline Total LN & 1.002 & 0.994 to 1.010 & 0.584 & & & \\
\hline Tumor Size $(n=1027)$ & 1.001 & 0.999 to 1.004 & 0.414 & & & \\
\hline Depth of invasion & & & 0.017 & & & 0.638 \\
\hline Mucosa or submucosa & ref & & & & & \\
\hline Proper muscle & 1.106 & 0.797 to 1.535 & & & & \\
\hline Subserosa & 1.068 & 0.800 to 1.424 & & & & \\
\hline Serosa & 1.304 & 0.964 to 1.765 & & & & \\
\hline Adjacent invasion & 1.549 & 1.105 to 2.173 & & & & \\
\hline mLNR stage. & & & $<0.001$ & & & $<0.001$ \\
\hline 0 & ref & & & ref & & \\
\hline 1 & 1.522 & 1.233 to 1.879 & & 1.496 & 1.209 to 1.851 & \\
\hline 2 & 2.378 & 1.910 to 2.962 & & 2.295 & 1.834 to 2.872 & \\
\hline 3 & 3.413 & 2.779 to 4.191 & & 2.269 & 2.648 to 4.036 & \\
\hline $\begin{array}{l}\text { Adjuvant radiotherapy (ART/ } \\
\text { no-ART) }\end{array}$ & 0.948 & 0.795 to 1.129 & 0.546 & & & \\
\hline
\end{tabular}

Abbreviations: HR:hazard ratio;API, Asian or Pacific Islander; LN, lymph node; mLNR: metastastic lymph node ratio; ART: Adjuvant radiotherapy.

defined as the number of positive nodes divided by the total examined nodes. As shown in the Figure 1, the best cutoff points for mLNR were $17.0 \%$ and $38.0 \%$. Therefore, the mLNR were classified into four groups, as the following intervals. The mLNRs $0: \operatorname{mLNR}=0 \%$;
mLNRs $1: 0 \%<\operatorname{mLNR}<17.0 \%$; mLNRs $2: 17.0 \%<$ mLNR $<38.0 \%$; mLNRs $3: 38.0 \%<\operatorname{mLNR}<100 \%$. 5 -year DSS for the 4-level mLNR were $52.1 \%, 36.8 \%$, $14.8 \%$ and $10.4 \%$, respectively. 


\section{Analysis of post-therapy prognostic factors}

In the univariate analysis, the depth of invasion, grade and mLNRs were significant risk factors for AGC after NRT, whereas, other factors such as age, gender, race, location, total examined lymph node (TLN) were not correlated with DSS. However, in the multivariate analysis, the depth of invasion lost statistical significance as a prognostic factor $(p=0.638)$.

According to the Cox regression analysis, we divided the patients into 8 groups (Group 1: mLNRs 0 and Grade I-II; Group 2: mLNRs 0 and Grade III-IV; Group 3: mLNRs 1 and Grade I-II; Group 4: mLNRs 1 and Grade III-IV; Group 5: mLNRs 2 and Grade I-II; Group 6: mLNRs 2 and Grade III-IV; Group 7: mLNRs 3 and Grade I-II; Group 8: mLNRs 3 and Grade III-IV) based on grade and mLNRs (Figure 2A). However, as shown in Figure $2 \mathrm{~A}$, there was no significant difference between Group 3 and 4 ( $\log \operatorname{rank} p=0.768)$, and also have insignificant difference in Group 5, 6 and $7(\log \operatorname{rank} p=0.955)$. As a result, we propose a novel Grade-lymph node Ratio (GR) staging system for all the AGC patients after NRT (As shown in Figure 2B). The G-R 1 was defined as mLNR equal to $0 \%$ and Grade I-II; G-R 2 as mLNR equal to $0 \%$ and Grade III-IV; G-R 3 as mLNRs 1; G-R 4 as mLNRs 2, or mLNRs 3 with Grade I-II; G-R 5 as mLNRs 3 and Grade III-IV. The observed 5-year DSS curves based G-R staging was shown in Figure 2B.
A

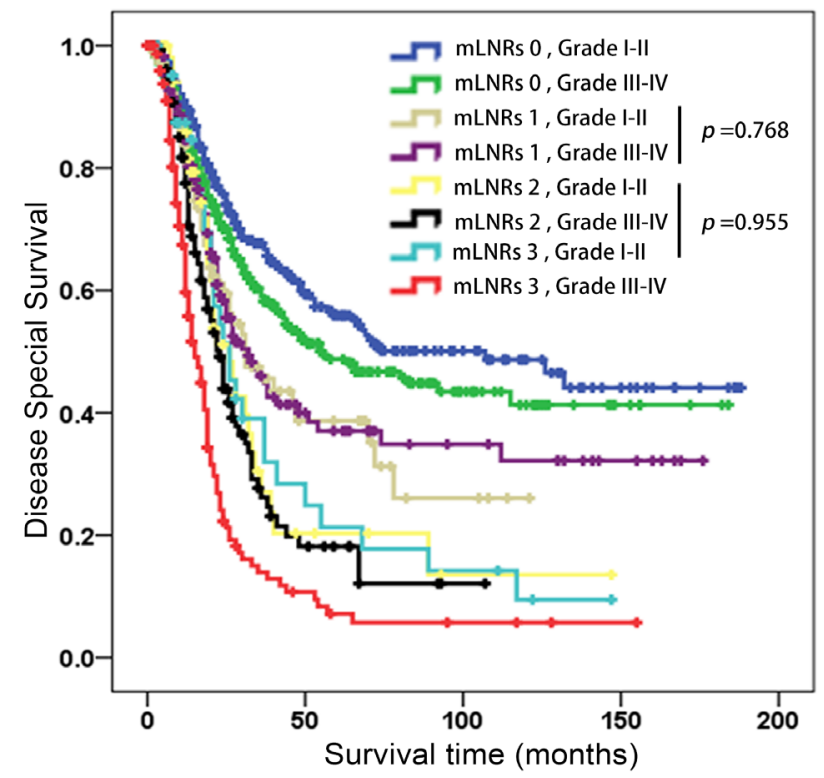

Comparison of predictive accuracy for G-R staging system single independent factors and AJCC staging system

The Area Under the ROC Curve (AUC) values were used to compare the discrimination for the G-R staging system and other prognostic models (mLNRs, AJCC staging system). The statistics power for discrimination between G-R staging system and AJCC staging system were compared in each time points. As shown in Table 3 and Figure 3, the AUC of G-R staging system were higher than mLNRs and AJCC staging system in both 3-year and 5-year time points ( $p=0.001,0.007$, respectively). Whereas, the AUC of G-R staging system were higher than AJCC staging system 1-year DSS but did not reach statistical significance $(p=0.282)$.

\section{DISCUSSION}

In the present study, we developed a novel G-R staging system for AGC patients after NRT. A total of 1,429 AGC patients who received surgery following NRT from SEER database between 1998 and 2012 were analyzed. We demonstrated that the new G-R staging system has a more-accurate 3-year and 5-year DSS prediction than the AJCC staging system ( $p$ value, $<0.001$, 0.008 , respectively).

The survival benefit of neoadjuvant therapy had been investigated in various tumors, including esophageal, pancreatic and rectal cancers. [16-18] However, the prognostic value of post-therapy pathological

B



Figure 2: A. The patients were grouped into 8 groups and validated Kaplan-Meier Curve. B. The patients were grouped into 5 groups and validated Kaplan-Meier Curve. Abbreviation: mLNRs, metastatic lymph node ratio stage; G-R stage, Grade-lymph node Ratio. 
A

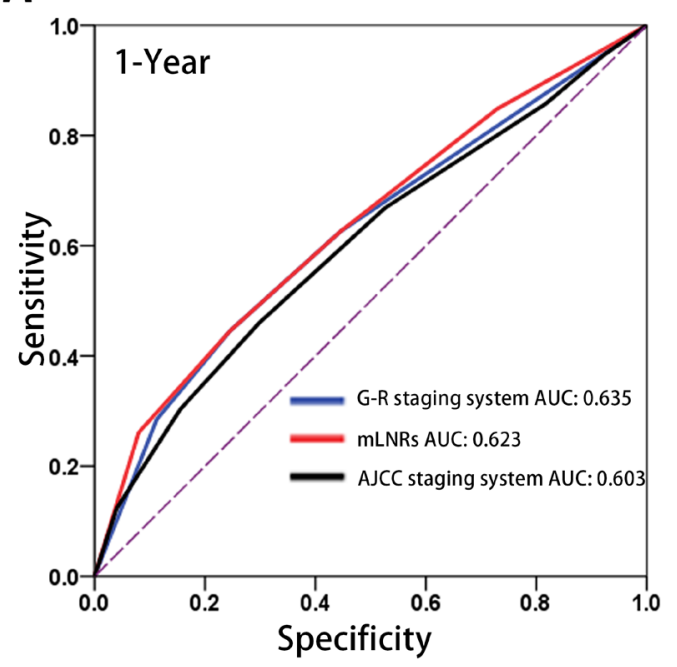

B

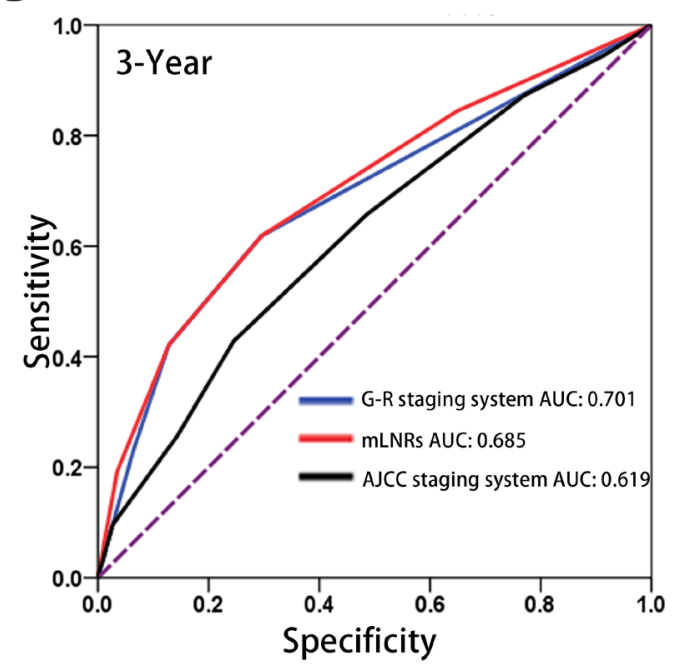

C



Figure 3: Comparison for the AUC of G-R staging system predicted, AJCC staging system and mLNRs to preidciton DSS at 1-yearA., 3-yearB., 5-yearC. Abbreviation: AUC, areas under the receiver operating curves; mLNRs, metastatic lymph node ratio stage; G-R stage, Grade-lymph node Ratio; DSS, disease special survival. 
Table 3: Comparison of predictive accuracy of DSS for G-R staging system, single independent factor and the 7th AJCC staging system in each time points

\begin{tabular}{|l|c|c|c|c|c|c|c|}
\hline \multicolumn{1}{|c|}{ Time points } & \multicolumn{2}{|c|}{ G-R staging system } & \multicolumn{2}{c|}{ mLNR stage } & \multicolumn{2}{c|}{ AJCC staging system } & \\
\hline & AUC & $\mathbf{9 5 \%}$ CI & AUC & $\mathbf{9 5 \% C I}$ & AUC & $\mathbf{9 5 \% C I}$ & $\boldsymbol{P}^{*}$ \\
\hline 1-Year & 0.635 & 0.592 to 0.679 & 0.623 & 0.579 to 0.666 & 0.603 & 0.559 to 0.647 & 0.282 \\
\hline 3-Year & 0.701 & 0.668 to 0.735 & 0.685 & 0.651 to 0.720 & 0.619 & 0.583 to 0.656 & 0.001 \\
\hline 5-Year & 0.699 & 0.661 to 0.738 & 0.683 & 0.644 to 0.721 & 0.619 & 0.575 to 0.662 & 0.007 \\
\hline
\end{tabular}

*:The $p$ value in the AUC were the G-R staging model compared with AJCC staging system.

Abbreviations: DSS, disease special survival; AUC, Area Under the ROC Curve; AJCC, American Joint Committee on Cancer.

characteristics in gastric cancer is still controversial. In 1999, Andrew ML et al analyzed 83 western AGC patients who were treated with neoadjuvant chemotherapy form three phase II trials. [13] With 26 months followup, the authors demonstrated that all the post-therapy T-N-M stage were not correlated with patients' survival. In contrast, Kazumasa FJ et al analyzed 70 Asian AGC patients after neoadjuvant chemotherapy in 2012, and the authors identified that the post-therapy nodal status is significantly associated with patients' overall survival. [12] In fact, indicators that independently and optimally reflect AGC patients' survival who received NRT had not been discovered. In 2005, Ajani JA et al conducted a study to investigate prognosis factors for overall survival for AGC patients after neoadjuvant chemoradiotherapy. [14] A total of 41 AGC patients from M.D. Anderson Cancer Center were analyzed. The authors found that the posttherapy T-N-M stage was associated with overall survival. The findings were interesting, however, the samples were small, and the patients' histological type had not been analyzed. In addition, all of the AGC patients in those studies were form tertiary care institutions that specialize in the treatment of malignancies, and the patients may have different characteristics from community institutions.

Currently, our study first review of a large data from national cancer registry, and established a novel G-R staging system for AGC patients after NRT. Although the conventional AJCC staging system represents an optimal tool in the field of gastric cancer, it is unclear whether this staging system suitable for gastric cancer patients after neoadjuvant therapy. [19] In fact, the known factor posttherapy depth of invasion after surgery held statistical significance in the univariate analysis, however, it did not maintain significance in the multivariate analysis $(p$ $=0.638)$ which was consistent with previous studies. [12, 13] Therefore, the AJCC staging system based on depth of invasion, nodal status and metastatic status may not be applicable for AGC patients after NRT. In contrast, the histology grade and mLNR were the only two prognosis factors correlated with DSS both in univariate and multivariate analysis. Based on this findings, we established a novel classifier for AGC patients after NRT. The G-R staging system appeared to have a more-accurate
DSS prediction than AJCC staging system or single independent factors. Since approximately $50 \%$ of the gastrectomy cases included in the SEER database came from community institutions, it is inconceivable that the G-R staging system has a broader applicability. [20]

The completed (R0) resection with D2 lymphadenectomy was the only potential curative for GC patients. [4] Since resection with D2 lymphadenectomy had not been widely performed in United States, the variable whether the patient received D2 lymphadenectomy was not included in this study. Additionally, although the previous studies demonstrated that the R0 resection was a significant risk for patients' survival, such direct evidence is unavailable because that SEER database did not collect the information of gastrectomy surgical margin status. [21] Given that the current study was a retrospective study, only the patients who had complete information were included in present analysis, there may be a selection bias. In addition, in the univariate analysis and multivariate analysis, the number of positive lymph node was also associated with patient's survival. The discrimination of mLNRs was better than that of positive lymph node number, but the difference was insignificant (data not shown). Given that the positive lymph nodes number identified depends on the pathologic procedure and surgical scope, we used mLNRs instead of positive lymph nodes number in the new classifier. [22]

Since the G-R staging system have a more-accurate survival prediction, it would be favor for designing postoperative treatment, particularly, which stage patients can obtain survival benefit from adjuvant radiotherapy after surgery. However, the difference of adjuvant radiotherapy were not correlated with DSS in each G-R stages (detailed data unshown). However, these findings should be interpreted with caution. The reasons are as follows: Firstly, there is missing information regarding the use of adjuvant chemotherapy. It is possible that patients may have received adjuvant chemotherapy after surgery, resulting in a potential confounder in this study. Secondly, the possibility of selection bias could be acknowledged, since the current analysis was not based on a randomized patient population. Thirdly, since there were only 60 patients underwent adjuvant radiotherapy included in this 
study, it may lead to a bias result.

In conclusion, the current large, general populationbased study demonstrated that the post-therapy pathological characteristics were associated with the survival of AGC patients after NRT. The post-therapy grade and mLNR were the only two predictors for those patients. Based on this finding, the novel G-R staging system showed optimal accuracy of survival prediction for AGC patients after neoadjuvant therapy. Through this classifier, clinicians can estimate the survival of the AGC patients after NRT more precisely.

\section{METHODS AND PATIENTS}

\section{Surveillance, epidemiology, and end results (SEER) database}

The SEER program, a large population-based collaboration program, was surveyed by the National Cancer Institute. A total of 18 population-based cancer registries were participated in this program, and the data are updated annually. It collects and provides approximately 26\% American population's cancer incidence and survival data.

Gastric cancer (ICD-O-3 code within the range of $8000-8152,8154-8231,8243-8245,8250-8576,8940-$ 8950 , and 8980-8990) undergoing NRT between January 1998 and December 2012 were eligible for current study. The inclusion criteria were as follows: 1) Patients without distant metastasis; 2) patients received gastrectomy (Surgery code within the range of 30-80); 3) patients received radiotherapy before surgery.

\section{Statistical methods}

The data of patients' clinicpathological characteristics such as age at diagnosis, gender, race, marital status, surgery, tumor site, size, histology, grade, depth of invasion, number of positive lymph node (PLN) and TLN were collected. The primary endpoint was DSS, which was defined as the time form surgery to cancerrelated death or the last follow-up. The pathological characteristics depth of invasion, lymph nodal stage and tumor stage were restaged according to the 7 th edition AJCC staging system.

Tumor grade is a measurement of how closely the tumor cells resemble the normal gastric cancer. Welldifferentiated (Grade I) and moderately-differentiated (Grade II) tumor cells closely resemble the tissue from normal gastric, whereas, poorly-differentiated (Grade III) and undifferentiated (Grade IV) tumor cells are disorganized and abnormal looking.

The mLNR was defined as the number of metastatic lymph nodes divided by the number of examined lymph nodes. A unique category mLNRs 0 was defined for patients with no regional positive lymph node, since those patients had significantly better prognosis than other patients ( $\mathrm{HR}=0.48, p<0.001)$. The patients with mLNR higher than $0 \%$ were categorized by X-tile (http:// www.tissuearray.org/rimmlab/). By this statistic tool, the continuous variables can divide into three groups. Associations between each group can be calculated by various standard statistical tests, including the log-rank test for survival and means tests for associations between other marker data. The X-tile can provide the optimal division of the data by $\mathrm{p}$ values obtained from a lookup table [23]

Independent risk factors were identified by the Cox regression analysis. DSS estimation and survival curves were performed by the Kaplan-Meier method and valided by the log-rank test. The Discrimination between the proposed G-R staging system and AJCC staging system was performed with ROC curve.

All analyses were performed by the software statistical package for social sciences (SPSS) version 19.0 (Chicago, IL), X-tile and the R software version 3.13 (http://www.r-project.org/). All the statistical tests were two sided. $p$ value $<0.05$ was considered to be statistically significant.

\section{ACKNOWLEDGMENTS}

The authors thank our colleagues from the Department of Head - neck and Thoracic Surgery for their kind help.

\section{CONFLICTS OF INTEREST}

The authors have no potential conflicts of interest.

\section{GRANT SUPPORT}

None.

\section{Authors' Contributions}

Conception and design: Shengying Wang, Rongxin, Zhang, Jianjun Liu

Development of methodology: Shengying Wang, Rongxin, Zhang

Collection and assembly of data: Jianjun Liu, Mingxue $\mathrm{Su}$

Data analysis and interpretation: Jianjun Liu, Mingxue $\mathrm{Su}$

Writing, review, and/or revision of the manuscript: All authors

Administrative, technical, or material support: Shengying Wang, Rongxin, Zhang

Study supervision: Shengying Wang, Rongxin, 
Zhang

Final approval of manuscript: All authors.

\section{REFERENCES}

1. DeSantis CE, Lin CC, Mariotto AB, Siegel RL, Stein KD, Kramer JL, Alteri R, Robbins AS and Jemal A. Cancer treatment and survivorship statistics, 2014. CA: a cancer journal for clinicians. 2014; 64:252-271.

2. Parkin DM. Global cancer statistics in the year 2000. The Lancet Oncology. 2001; 2:533-543.

3. Bertuccio P, Chatenoud L, Levi F, Praud D, Ferlay J, Negri $\mathrm{E}$, Malvezzi M and La Vecchia C. Recent patterns in gastric cancer: a global overview. International journal of cancer. 2009; 125:666-673.

4. Songun I, Putter H, Kranenbarg EM, Sasako M and van de Velde CJ. Surgical treatment of gastric cancer: 15-year follow-up results of the randomised nationwide Dutch D1D2 trial. The Lancet Oncology. 2010; 11:439-449.

5. Cunningham D, Allum WH, Stenning SP, Thompson JN, Van de Velde CJ, Nicolson M, Scarffe JH, Lofts FJ, Falk SJ, Iveson TJ, Smith DB, Langley RE, Verma M, Weeden S, Chua YJ and Participants MT. Perioperative chemotherapy versus surgery alone for resectable gastroesophageal cancer. The New England journal of medicine. 2006; 355:11-20.

6. Ajani JA, Mansfield PF, Janjan N, Morris J, Pisters PW, Lynch PM, Feig B, Myerson R, Nivers R, Cohen DS and Gunderson LL. Multi-institutional trial of preoperative chemoradiotherapy in patients with potentially resectable gastric carcinoma. Journal of clinical oncology. 2004; 22:2774-2780.

7. Ajani JA, Winter K, Okawara GS, Donohue JH, Pisters PW, Crane CH, Greskovich JF, Anne PR, Bradley JD, Willett C and Rich TA. Phase II trial of preoperative chemoradiation in patients with localized gastric adenocarcinoma (RTOG 9904): quality of combined modality therapy and pathologic response. Journal of clinical oncology. 2006; 24:3953-3958.

8. Trip AK, Poppema BJ, van Berge Henegouwen MI, Siemerink E, Beukema JC, Verheij M, Plukker JT, Richel DJ, Hulshof MC, van Sandick JW, Cats A, Jansen EP and Hospers GA. Preoperative chemoradiotherapy in locally advanced gastric cancer, a phase I/II feasibility and efficacy study. Radiotherapy and oncology : journal of the European Society for Therapeutic Radiology and Oncology. 2014; 112:284-288.

9. Ajani JA, Mansfield PF, Lynch PM, Pisters PW, Feig B, Dumas P, Evans DB, Raijman I, Hargraves K, Curley S and Ota DM. Enhanced staging and all chemotherapy preoperatively in patients with potentially resectable gastric carcinoma. Journal of clinical oncology. 1999; 17:24032411.

10. Newton AD, Datta J, Loaiza-Bonilla A, Karakousis GC and Roses RE. Neoadjuvant therapy for gastric cancer: current evidence and future directions. Journal of gastrointestinal oncology. 2015; 6:534-543.

11. Yang Y, Yin X, Sheng L, Xu S, Dong L and Liu L. Perioperative chemotherapy more of a benefit for overall survival than adjuvant chemotherapy for operable gastric cancer: an updated Meta-analysis. Scientific reports. 2015; $5: 12850$.

12. Fujitani K, Mano M, Hirao M, Kodama Y and Tsujinaka T. Posttherapy nodal status, not graded histologic response, predicts survival after neoadjuvant chemotherapy for advanced gastric cancer. Annals of surgical oncology. 2012; 19:1936-1943.

13. Lowy AM, Mansfield PF, Leach SD, Pazdur R, Dumas P and Ajani JA. Response to neoadjuvant chemotherapy best predicts survival after curative resection of gastric cancer. Ann Surg. 1999; 229:303-308.

14. Ajani JA, Mansfield PF, Crane CH, Wu TT, Lunagomez S, Lynch PM, Janjan N, Feig B, Faust J, Yao JC, Nivers R, Morris $\mathrm{J}$ and Pisters PW. Paclitaxel-based chemoradiotherapy in localized gastric carcinoma: degree of pathologic response and not clinical parameters dictated patient outcome. Journal of clinical oncology. 2005; 23:1237-1244.

15. An JY, Kim HI, Cheong JH, Hyung WJ, Kim CB and Noh SH. Pathologic and oncologic outcomes in locally advanced gastric cancer with neoadjuvant chemotherapy or chemoradiotherapy. Yonsei medical journal. 2013; 54:888894.

16. Chirieac LR, Swisher SG, Ajani JA, Komaki RR, Correa AM, Morris JS, Roth JA, Rashid A, Hamilton SR and Wu TT. Posttherapy pathologic stage predicts survival in patients with esophageal carcinoma receiving preoperative chemoradiation. Cancer. 2005; 103:1347-1355.

17. Breslin TM, Hess KR, Harbison DB, Jean ME, Cleary KR, Dackiw AP, Wolff RA, Abbruzzese JL, Janjan NA, Crane CH, Vauthey JN, Lee JE, Pisters PW and Evans DB. Neoadjuvant chemoradiotherapy for adenocarcinoma of the pancreas: treatment variables and survival duration. Annals of surgical oncology. 2001; 8:123-132.

18. Ruo L, Tickoo S, Klimstra DS, Minsky BD, Saltz L, Mazumdar M, Paty PB, Wong WD, Larson SM, Cohen AM and Guillem JG. Long-term prognostic significance of extent of rectal cancer response to preoperative radiation and chemotherapy. Annals of surgery. 2002; 236:75-81.

19. Edge SB BD CC, Fritz AG et al. AJCC Cancer Staging Manual 7th. Springer. 2010; New York.

20. Hoffman KE, Neville BA, Mamon HJ, Kachnic LA, Katz MS, Earle CC and Punglia RS. Adjuvant therapy for elderly patients with resected gastric adenocarcinoma: populationbased practices and treatment effectiveness. Cancer. 2012; 118:248-257.

21. Bonenkamp JJ, Hermans J, Sasako M, van de Velde CJ, Welvaart K, Songun I, Meyer S, Plukker JT, Van Elk P, Obertop H, Gouma DJ, van Lanschot JJ, Taat CW, de Graaf PW, von Meyenfeldt MF and Tilanus H. Extended 
lymph-node dissection for gastric cancer. The New England journal of medicine. 1999; 340:908-914.

22. Wang W, Xu DZ, Li YF, Guan YX, Sun XW, Chen YB, Kesari R, Huang CY, Li W, Zhan YQ and Zhou ZW. Tumor-ratio-metastasis staging system as an alternative to the 7th edition UICC TNM system in gastric cancer after D2 resection - results of a single-institution study of 1343 Chinese patients. Annals of oncology. 2011; 22:2049-2056.
23. Criminisi A SJ. Decision forests for computer vision and medical image analysis. Springer. 2013. 